\title{
Compliance with Tax Laws in the Russian Federation: Trust or Control
}

\author{
Murat Aliev ${ }^{1}$, Ekaterina Milovanova ${ }^{1}$, Irina Moiseenko ${ }^{1}$, Vladimir Molodykh ${ }^{2}$ \\ ${ }^{1}$ Piatigorsk Institute (branch) Plekhanov Russian University of Economic, \\ 8 Kuchury St., Pyatigorsk, 357500, Russia \\ ${ }^{2}$ North-Caucasus Federal University, 1 Pushkin str., Stavropol, 355017, Russia
}

\begin{abstract}
Tax evasion processes have been analyzed using the "slippery slope" concept, which has made it possible to assess the influence of socio-psychological and "rational" factors on the behavior of taxpayers in the context of voluntary and involuntary compliance with the tax laws. The representatives of small and medium businesses acted as the respondents, who evaluated their behavior in the framework of procedural, distributive, and punitive justice. The simulation results have shown that compliance with tax legislation, regardless of its voluntary or involuntary nature, depends on the level of trust in public authorities and the subjective perception of justice of the current tax system.
\end{abstract}

Keywords - Tax evasion, slippery slope model, behavioral economics.

\section{Introduction}

In most economic studies concerned with the empirical analysis of tax crime, theoretical hypotheses confirm the influence of a number of factors on the process of tax evasion. The discrepancies in the results obtained can be explained by the difficulties in the assessment of the real extent of this phenomenon, which negatively affects the quality of empirical

DOI: 10.18421/TEM101-39

https://doi.org/10.18421/TEM101-39

Corresponding author: Vladimir Molodykh,

North-Caucasus Federal University.

Email: vladimir.molodykh@rambler.ru

Received: 09 October 2020.

Revised: 30 January 2021.

Accepted: 06 February 2021.

Published: 27 February 2021.

(cc) BY-NC-ND (C) 2021 Murat Aliev et al; published by UIKTEN. This work is licensed under the Creative Commons Attribution-NonCommercial-NoDerivs 4.0 License.

The article is published with Open Access at www.temjournal.com analysis and, as a result, creates additional difficulties [14], [11].

Conversely, the epistemological debate between proponents and opponents of an empirical study of economic science is fundamental, which does not allow one to benefit from the "ongoing methodological and empirical revolution" [6]. Despite the fact that in the humanities there is a "revolution of confidence in applied econometrics" [6], caused by an increase in the quality of the initial information, ease of processing, reaching a new level of randomized trials, experimental and field research, laboratory experiments, the approaches of behavioral and experimental economics are not so popular in Russia.

The article is structured in accordance with this. The limitations of use of the empirical approach to analyze the behavior of taxpayers and the possibility of overcoming it within the framework of an interdisciplinary approach are considered. To this end, the existing difficulties of an empirical analysis of tax evasion processes in the framework of the neoclassical paradigm and behavioral economics are considered. The "slippery slope" concept is used as a tool to identify the taxpayers' behavior, based on the constructed model, the recommendations on the possibility of its practical use are given, taking into account the existing restrictions, and the prospects of interaction between the academic community and public authorities in the framework of studies on the solution of the problems related to tax evasion reduction.

\subsection{Problems of Using Empirical Approaches in the Analysis of Tax Evasion}

Empirical research on tax compliance issues is complicated by a number of objective and subjective reasons. The main problem is the lack of accurate and objective data both at the macro level, for example, on the extent of tax evasion, and at the micro level - the incentive for the taxpayers to choose deviant models of behavior. This problem is based on several reasons: the high latency of tax crimes, the lack of direct victims, the reluctance of 
entrepreneurs to give honest answers to researchers' questions due to the recognition of the illegality of tax evasion, and the receipt of socially significant answers if, for example, students participate in the experiment.

In this regard, the authors would like to note several inventive approaches to solve this problem. For example, in the study [9], the matters of cigarettes excise tax evasion were studied based on a random sample obtained from empty cigarette packs collected in garbage bins before and after the increase in excise tax rates. In Italy, there is the practice of collecting voluntary and anonymous messages through the website of all purchases without issuing a check by the seller. The magnitude of the shadow economy was estimated using the images of night lights visible from space [20], and tax evasion from sales based on online shopping information [5], [23].

The use of official data, which refers to the information collected primarily for administrative purposes, is somewhere between direct and indirect methods [27], [31]. The data is collected by government agencies and other organizations for registration, operational, and accounting purposes. Unlike sample-based archival data, official data is often applied to the entire population concerned. Despite the cost, the US Internal Revenue Service (IRS) regularly conducts research to identify the evidence of tax evasion through random tax returns since the 1960s. Initially, this was carried out as part of the implementation of the Taxpayer Compliance Measurement Program (TCMP), later as part of the National Research Program (NRP). The main goal of this study is purely applied and includes the improvement of the procedures for declarations collection for an in-depth audit. This makes it possible to compare the actually declared income with the "true income" and approximately calculate the "tax gap" magnitude.

Another source of information is the World Values Survey (http://www.worldvaluessurvey.org), which provides country-specific surveys of individual and social values. Some researchers use the data on tax amnesties as a direct approach to obtaining information, where the data on the income of amnesty participants presented in declarations is used as an accurate indicator of tax evasion.

Based on the generated array of statistical information, researchers are actively studying tax crime: assessing the size and nature of the "tax gap", the effect of income on the likelihood of tax evasion, tax evasion among the self-employed population, small and medium-sized businesses. At the same time, discussions about the methods of data collection and the quality of the information received remain opened [25], [31]. However, despite the existing scepticism, there is an increasingly widespread provision saying that new technologies for data collection and processing increase not only the accuracy of empirical studies but also the possibility of their use in practice [6].

Tax evasion is often considered a manifestation of the informal economy in the economic literature, but these phenomena are not identical. For example, a reduction in the tax base for income tax through the use of leasing schemes can be qualified as tax evasion in accordance with Article 199 of the Criminal Code, but it will not be part of the informal economy. An entrepreneur who has not been registered with the tax authorities and conducts illegal business activities (Article 171 of the Criminal Code of the Russian Federation) also does not pay taxes, therefore these actions, which entailed tax evasion, will be part of the informal economy. In both examples, there is an illegal reduction in tax liabilities, however, in the first case, aggressive tax planning may take place, i.e. the taxpayer could violate the law without intent, therefore, the fact of evasion was absent regardless of the size of the damage caused (the objective side of the tax crime), this act cannot be qualified as a crime, but it can be classified as an offense, since the subjective side of the tax crime is absent.

Thus, the main difficulty for empirical research is the lack of reliable statistical information on the behavior of taxpayers. Existing arrays of statistical information rarely contribute to accurate identification of the impact of individual factors, for example, the changes in tax administration costs, or the amount of penalties.

One of the main problems is the lack of a methodology for relatively accurate determination of the extent of tax evasion. This problem is associated with a high latency of tax violations, since the tax authorities are not able to identify all facts of tax evasion, or to determine in full the amount of hidden income when conducting a tax audit. As a result, situations arise where tax violators can be considered bona fide taxpayers, and the level of evasion by others will be lower than in reality.

All this distorts the influence of factors in tax evasion models for which an econometric model of "detection controlled estimation" was developed, which makes this problem possible to solve. Prinz et al [21] analyzed the use of this model and found that the consideration of the partial determination of tax evasion changes the standard models for assessment of the taxpayer behavior. In their opinion, the use of this model makes it possible not only to improve the estimates obtained by taking into account the problems of partial identification but also to obtain more accurate information on the extent of tax evasion and the efficiency of tax audits. For the US 
case, the following conclusions were drawn about the effectiveness of the tax control system:

- the effectiveness of control activities in the IRS is such that for one dollar of unpaid tax identified there is one dollar of undetected understate tax;

- there are very high differences among the employees of tax authorities in the evaluation of the number of facts revealed by them and the extent of tax evasion;

- the amount of unpaid taxes is lower in the case when tax returns are prepared with the help of tax consultants.

Another approach that made it possible to expand the scope of the use of mathematical models of taxpayer behavior in empirical studies was presented by Slemrod and Gillitzer [24]. The author proposed to estimate the scale of tax evasion based on a comparison of the taxpayer's declared income distributed within quantiles.

Thus, in the majority of studies concerned with empirical analysis, theoretical hypotheses also find confirmation of the influence of the main factors on the process of tax evasion. The discrepancies in the results obtained are due to the fact that it is difficult to assess the real extent of tax evasion, which negatively affects the quality of empirical analysis and, as a result, creates additional difficulties. Also, the considered models practically do not take into account the possibility of a diverse selection of strategies of behavior by tax authorities. The use of the neoclassical approach in analyzing the behavior of taxpayers in the context of tax evasion mainly leads to the consideration of cognitive stereotypes that arise on the basis of postulating rational behavior of economic agents and ignoring the effects of motivation and subjective perception of reality.

\subsection{The "Slippery Slope" Concept as a Basis for the Analysis of Taxpayer Behavioral Strategies}

The study of tax crime begins with the model proposed in [1], which proposed to analyze tax evasion as an individual solution in the face of uncertainty, which depends on the amount of income, the tax rate, the probability of detection, and the size of penalties. In their work, the authors relied on the game theory axioms, as well as on the economic theory of crime [8]. Accordingly, taxpayers seek to maximize their expected utility by using a tax evasion strategy if they believe that no further punishment will follow.

The importance of alternative factors unrelated to classical economic theory, such as the justice of the tax system and social norms of behavior accepted in society, was first substantiated in [26]. He noted that unfair treatment compared to others or in relation to the benefits of public goods provided could be a determining factor in the adoption by taxpayers of a specific behavior strategy.

Taxpayers make decisions, not only guided by financial gain; they also comply with tax laws if they consider it to be morally correct. For example, personal tax morality standards significantly mitigate the impact of penalties and audit likelihood, and vice versa - the deterrent effect of these measures is weakened in cases where taxpayers have low tax morality. This is especially important from a practical point of view, as taxpayers with stable and strong personal norms demonstrate lower levels of tax evasion. The study [4] also emphasizes the impact of tax ethics on decision making and potential losses that may result from moral standards. In addition, stereotypes of behavior adopted in social groups influence decisions of taxpayers. If taxpayers find out that evasion is common among the group with which they identify themselves, they felt less guilty of tax evasion. Conversely, a high level of tax ethics can strengthen compliance with the law, as taxpayers may feel guilty and ashamed.

The concept of compliance with tax legislation "slippery slope", proposed in [16], makes it possible to integrate and analyze the ambiguous influence of economic and psychological factors on taxpayer choice of deviant behaviors and has gained great popularity [7], [10], [22].

In the model, the motives for tax compliance are divided into two groups: involuntary and voluntary. In this context, traditional factors, such as the likelihood of an audit and the size of penalties, force the taxpayer to comply with the law, while factors of a psychological and social nature, for example, the perception of a fair tax system or prevailing stereotypes of social behavior, can have a positive effect on the level of tax discipline and promote voluntary compliance with tax laws. Thus, the "slippery slope" model makes it possible to analyze the choice of a taxpayer based on two aspects: trust in government bodies and the effectiveness of tax control.

It should be noted that the concepts of "justice" or "trust" are multifaceted, and the relationship between them and tax evasion is complex and not always obvious. Since the 1990s, there has been a significant increase in attention to this problem, primarily from the behavioral and experimental economies [3], [24], however, as part of this study, it is important to identify the level of trust in government and the perception of fairness in the current tax system, not the factors that shape them.

The second aspect of the "slippery slope" concept is to evaluate the anti-tax avoidance policy that meets the objective of preventing future crimes through the use of tax control tools and penalties. These tools can 
be considered in the framework of the game "policemen and robbers", where the punishment for tax evasion will be adequate retribution for behavior that harms society, i.e. the counteraction policy is also indirectly connected with trust in authorities. For example, if fines are perceived as too low, then this can serve as an indicator of the weakness of power and, therefore, undermine trust. Excessively high fines, especially in the face of the complexity of tax legislation and the presence of gaps in it, also negatively affect the level of tax discipline, as this undermines the perception of punitive justice, and can provoke taxpayers to relapse, as they seek to compensate for the unjustly incurred (from their point of view) losses and will repeatedly evade taxes.

The "slippery slope" model became the main one for a series of empirical studies (for example [18], [19]) and its main premises were formalized in [21].

Thus, in spite of the fact that the "external" factors characterizing the rational choice of taxpayers (the amount of tax burden, the probability of an audit and the detection of tax evasion, the amount of penalties) play an important role in explaining the taxpayer behavior, the "internal" variables (personal ethics and motivation, social norms and stereotypes) also have a significant influence on the choice of an appropriate behavior strategy.

\section{Materials and Method}

In this study, the "slippery slope" model was tested on the basis of a survey of small and medium-sized businesses conducted in the regions of the North Caucasus. The choice of this group is due to the fact that self-employed citizens and small businesses have more opportunities for tax evasion, for example, compared with the employees or corporations [17]. Entrepreneurs can also adequately describe the work of tax authorities, the strength of administrative pressure, the size of the tax burden, i.e. to evaluate the effectiveness of control activities and various aspects of the justice of the current tax system in the context of compliance with tax legislation.

In accordance with the "slippery slope" assumptions, the following hypotheses were tested:

- trust in public authorities is a significant factor stimulating the taxpayer to voluntarily comply with the law;

- the effectiveness of tax control is an important factor for legislation enforcement;

- both trust and control are significant factors that increase the level of tax discipline, regardless of the taxpayer's motivation to pay or evade taxes.

Ultimately, the taxpayer's perception of the tax system as fair will positively affect its level of confidence in the government, as well as contribute to voluntary compliance with the law.

In accordance with the objectives of the study, there are three types of justice considered in social psychology [29]: procedural justice; distributive justice; punitive justice.

In the context of tax evasion, procedural justice is manifested in the neutrality of administration procedures, transparency of tax control procedures, the complexity of the legal framework, and respect for taxpayers by the tax authorities [30], [32].

Distributive justice refers to the equivalent exchange of resources in relation to the potential benefits paid by taxes and the costs of tax administration. The key role is played here by the taxpayer's perception of the level of its tax burden, including in comparison with other individuals or groups. If the tax burden is perceived as more severe compared to others, then this negatively affects the level of tax morality [12].

Punitive justice refers to the appropriateness and proportionality of the application of sanctions in the case of violations of the law. There is plenty of evidence [34] that unreasonable prosecution, excessive pressure from regulatory authorities, and unfairly high fines cause a negative attitude toward the tax system. As a result, this leads to a decrease in the level of trust in the authorities and incites the taxpayers to choose a tax evasion strategy. At the same time, it should be borne in mind that the parameters characterizing punitive justice (first of all, the probability of an audit and the amount of penalties) relate not only to psychological factors but also to traditional ones, therefore their influence on the formation of a "slippery slope" will be dual [15].

The survey methodology, construction and subsequent interpretation of the grading scale are based on adapted research results [33] concerned with the "slippery slope" model. Answers to all questions are given based on a 7-point scale (from 1 - complete disagreement to 7 - full agreement). The integral indicator of tax compliance is calculated by averaging the subscales for each respondent. The questions are combined into two groups: characterizing the level of trust in the authorities and the effectiveness of punitive justice procedures (the questionnaire questions are presented in Appendix $1)$.

In accordance with the methodology, the level of voluntary compliance with tax legislation is assessed as an everyday procedure (question 1 in the questionnaire) and in the context of a hypothetical lack of tax control procedures (question 2 in the questionnaire). Involuntary compliance with tax laws is analyzed in the context of the following factors: the likelihood of an audit (question 3 in the questionnaire) and the amount of penalties (question 
4 in the questionnaire), as well as "involuntary loss" (question 5 in the questionnaire). The perception of procedural fairness is assessed as the client-oriented behavior of tax authorities in relation to taxpayers, namely: objectivity (question 6 in the questionnaire), compliance with the rights of taxpayers (question 7 in the questionnaire), completeness of information (question 8 in the questionnaire), equality of treatment compared to other taxpayers (Question 9 in the questionnaire). Distributive justice is analyzed in general (question 10 in the questionnaire), taking into account the state benefits provided in return (question 11 in the questionnaire) by type of activity (question 12 in the questionnaire) in comparison with small businesses with a large tax burden (question 13 in the questionnaire) and tax benefits (question 14 in the questionnaire). Punitive justice is assessed in the context of the inevitability of punishment (question 15 in the questionnaire), the rigidity of the tax system (question 16 in the questionnaire), the effectiveness of punishment (question 17 in the questionnaire) and pressure from the tax authorities (question 18 in the questionnaire).

All answers are presented in the form of the Likert scale, where participants have to indicate their agreement on the relevant issue $(1=$ "I completely disagree", 7 = "I completely agree"). For further analysis, all variables are Z-transformed.

\section{Results}

The survey was attended by 192 representatives of small and medium-sized businesses from the regions of the North Caucasus. Statistical analysis of the results showed the following (Table 1). The average value for three factors (trust, power and voluntary compliance) varies within 0.1 , and the maximum is observed for involuntary compliance, i.e. despite the fact that the respondents highly value the importance of trust and the need to incite voluntary compliance with tax laws; nevertheless they put tax control procedures at the forefront. This also confirms the minimum value of the factor of involuntary compliance (3.2), i.e. all the respondents in the sample consider this factor important.

Table 1. Descriptive Statistics

\begin{tabular}{lccccc}
\hline Variables & Valid N & Mean & $\begin{array}{c}\text { Mini } \\
\text { mum }\end{array}$ & $\begin{array}{c}\text { Maxi } \\
\text { mum }\end{array}$ & $\begin{array}{c}\text { Std. } \\
\text { Dev. }\end{array}$ \\
\hline $\begin{array}{l}\text { Trust } \\
\text { Power }\end{array}$ & 192 & 3.78 & 1.92 & 6.27 & 1.32 \\
$\begin{array}{l}\text { Voluntary } \\
\text { compliance }\end{array}$ & 192 & 3.82 & 2.04 & 6.33 & 1.27 \\
$\begin{array}{l}\text { Involuntary } \\
\text { compliance }\end{array}$ & 192 & 4.59 & 1.98 & 6.25 & 1.08 \\
\hline
\end{tabular}

Source: developed by the authors
As shown in Table 2, the relationship between voluntary compliance with tax laws, trust in authorities, and the effectiveness of tax control turned out to be a significantly high level of positive correlation $(\mathrm{r}=.846 ; \mathrm{p}<.001)$. This confirms the thesis that trusts on the part of taxpayers in power, the presence of transparent and constant rules of the game stimulates compliance with tax laws. It should be noted (Figure 1) that the influence of the factors of power and trust is almost symmetrical, i.e. postulates in the framework of the "slippery slope" model are confirmed. It follows from this that tax control has also to be taken into account as a fundamental factor affecting voluntary compliance with legislation. However, in this case, not only the severity and inevitability of punishments for violations of tax laws come to the fore, but, above all, compliance with the principles of procedural justice. Taxpayers have to be sure that they will not be subject to excessive pressure from the tax authorities, violators will be identified, and if violations are found, the punishment will be proportionate.

Table 2. Voluntary compliance regression statistics

\begin{tabular}{lcccc}
\hline & b & SE (b) & $\boldsymbol{\beta}$ & SE ( $\beta$ ) \\
\hline Free participant & -0.212 & 0.263 & & \\
Trust & 0.502 & 0.047 & $0.614^{* * *}$ & 0.057 \\
Power & 0.578 & 0.049 & $0.678^{* * *}$ & 0.057 \\
\hline
\end{tabular}

Regression Summary for Dependent Variable: Voluntary compliance $R=0.91971981 R^{2}=0.84588452$ Adjusted $R^{2}=$ $0.83932641 F(2,47)=128.98 \quad p<0.0000$ Std.Error of estimate: 0.43373

Source: developed by the authors.

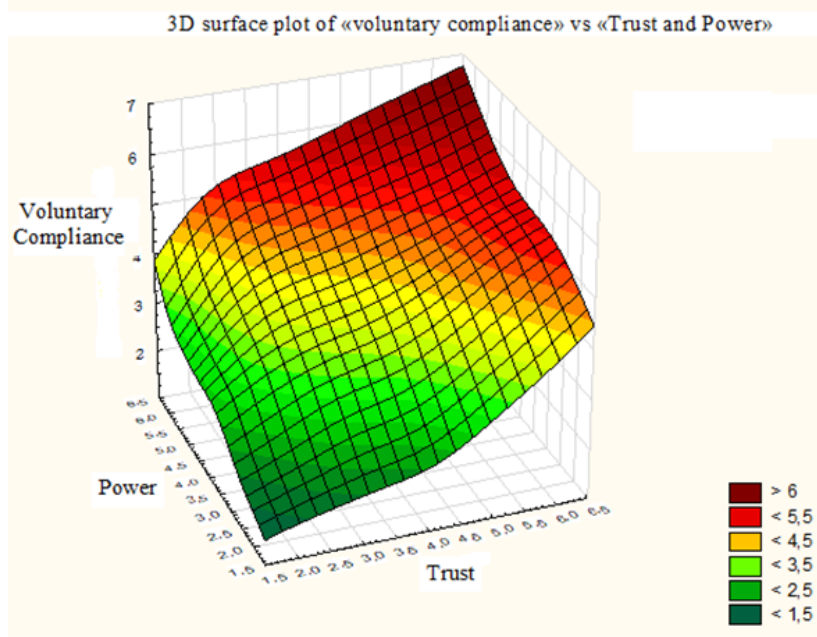

Source: developed by the authors.

Figure 1. Voluntary compliance with tax laws as a function of power and trust

Slightly different results were obtained as a result of the analysis of the voluntary compliance with tax legislation. As shown in Table 3, both factors included in the model turned out to be significant, as 
well as in the first case, a close direct relationship is observed. However, as can be seen from the figure, the graph does not correspond to the slippery slope model (Figure 2). In this case, the level of trust in the authorities does not have such a strong influence on the choice by taxpayers of deviant behaviors, as toughening control procedures. As a result, it is advisable to consider enforcing tax laws within the framework of the neoclassical concept of taxpayer behavior, where the main factors affecting their choice are the probability of detecting violations of the law and the amount of penalties. The significance of the confidence factor in this case allows concluding that the effects of trust between taxpayers and tax authorities can also arise in the framework of punitive justice. If sanctions are interpreted as legal and proportionate, then this will have a positive effect on the level of trust in the authorities. Although it should not be forgotten that excessive pressure, especially against scrupulous taxpayers, leads to a stronger sense of coercion, which can lead to an increase in tax evasion [13].

Table 3. Involuntary compliance

\begin{tabular}{lcccc}
\hline & b & SE (b) & $\boldsymbol{\beta}$ & SE $(\boldsymbol{\beta})$ \\
\hline Free participant & 1.367 & 0.134 & & \\
Trust & 0.124 & 0.024 & $0.175^{* * *}$ & 0.031 \\
Power & 0.705 & 0.025 & $0.955^{* * *}$ & 0.034 \\
\hline
\end{tabular}

Regression Summary for Dependent Variable: Involuntary compliance $R=0.97302396 R^{2}=0.94677562$ Adjusted $R^{2}=$ 0.94451075 F $(2,47)=418.03 p<0.0000$ Std. Error of estimate: 0.22085

Source: developed by the authors.

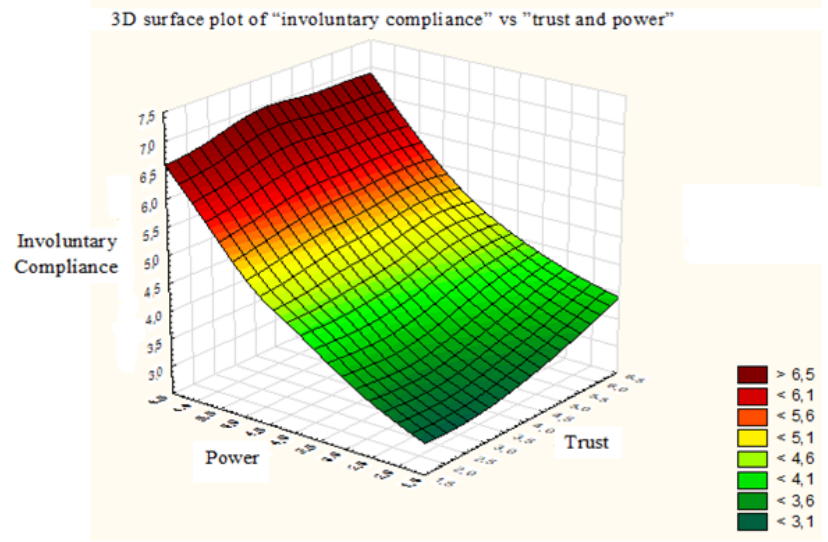

Source: developed by the authors.

Figure 2. Involuntary compliance with tax laws as a function of power and trust

Analyzing the results, some limitations of a methodological nature should be noted. The sample of representatives of small and medium-sized businesses was formed on the basis of the voluntary participation principle (only 192 of the 284 participants of the forum where the study was conducted agreed to participate in the questionnaire), which, possibly, could lead to bias in the estimates received. As noted in the study [2], the taxpayers with a high level of trust in the government and with a predominant motivation for voluntary compliance are more willing to participate in research.

Considering the prerequisites for voluntary and involuntary compliance with tax legislation, the social desirability of the answers received should be taken into account, i.e. it should be recognized that the possibility of paying taxes solely through inspections and fines can be more difficult for the respondents than choosing answers with a voluntary payment because of moral obligations. It is also necessary to bear in mind that, considering trust as the result of a mediated relationship between procedural and distributive justice and voluntary compliance with tax laws, it is difficult to assess how strongly the indirect effect of punitive justice and justice is. This is due to the fact that, referring to deterrence, one can observe the indirect effect of trust and power, which can be interpreted as an opportunity to influence tax discipline with deterrence measures either through trust or through force. It is also important to distinguish between institutional and interpersonal trust [4], since social norms can be formed under the influence of various strata of society and not be associated with trust in government bodies, the assessment of the influence of which was the aim of this study.

In general, the results showed that compliance with tax legislation, regardless of whether it is voluntary or mandatory, depended on the level of trust in government and was an important factor in reducing the scale of tax evasion.

Based on this, the positive aspect is that the principles of a risk-based approach to working with taxpayers are actively introduced in the activities of the Federal Tax Service of Russia, which are aimed at increasing the level of trust in tax authorities. This is manifested primarily in a decrease in the number of field tax audits, the ability of taxpayers to independently assess risks based on the criteria of the integrity of taxpayers, etc. At the same time, the tax authorities in their activities strive to use a strategy that has three sides: regulatory, law enforcement, and motivational. In accordance with it, all taxpayers are divided into three groups according to the level of risk, and each has its own behavior strategy. In relation to the first group, which includes bona fide taxpayers, a customer-oriented approach is used. In the second group, monitoring of taxpayers and their grouping is carried out in order to further stimulate their transition to the first group due to closer and loyal interaction with tax authorities. The third group includes taxpayers who systematically evade taxes. For them, they apply a strategy related to increased levels of tax control in order to minimize the ability of taxpayers to evade taxes. 
Despite the positive results achieved in the fight against tax evasion, it has to be borne in mind that a general tightening of the tax administration system can adversely affect the level of tax discipline. For example, based on an IPT survey conducted in 2017 in Russia, $78 \%$ of taxpayers noted increased pressure from the tax authorities, and a number of law firms have noted stricter liability for tax violations based on an analysis of law enforcement practice over the past three years.

Thus, the results obtained demonstrate the importance of using a customer-oriented model in the interaction of taxpayers and tax authorities as the basis for reducing the scale of tax evasion. However, more extensive research is required at the subnational level or in a sectoral context, in order to identify the specifics of taxpayer behavior and the principles of deviant behavior patterns.

\section{Conclusion}

The "slippery slope" model considered herein can become the basis for the implementation of a clientoriented paradigm within the existing tax administration system, which will contribute to the reduction of the tax crime level. However, its implementation is associated with the need to answer questions and solve a number of problems, both of a methodological and applied nature:

- the lack of a universal methodology for evaluation of the impact of trust in public authorities on compliance with tax laws;

- the need to consider the heterogeneity of taxpayer groups;

- what role do social norms and accepted stereotypes of behavior in society play in the choice of a tax evasion strategy by the taxpayers?

- how can the subjectivity factor be isolated in the evaluation of the perception of the justice of the tax system?

- how do the "intrinsic motivation" of taxpayers to pay taxes and "punitive justice" correlate?

- how does the introduction of a risk-based approach in the control activities of tax authorities affect the behavior of taxpayers, etc.?

Despite all the complexity, the solution to these problems is possible within the framework of closer interaction between the academic community and public authorities. Statistical data obtained as a result of experimental and field studies become an important source of information for an empirical analysis of the causes and factors affecting the choice of deviant behavior patterns by taxpayers. Most of these studies are conducted in the United States based on data from the IRS and in European countries, where the tax authorities in the last 10-15 years have begun to actively cooperate with the academic community at the Joint Research Center at the European Commission.

This experience of cooperation can be very useful for Russia for a number of reasons. The state authorities have not yet come to the conclusion that their own experience in interacting with taxpayers is not enough to predict the consequences of not only changes in the tax policy of the state as a whole but also of individual changes in tax legislation. In the context of combating tax crime, the latter case is especially important, since "minor boosts are an attractive option for influencing the taxpayer, because small changes can have significant consequences" [28].

Joint field experiments conducted in cooperation with the Federal Tax Service will make it possible to generate the necessary arrays of statistical information, the placement of which in the public domain will reduce the cost of research and increase their diversity. Such cooperation will also contribute to the emergence of a synergistic effect, since tax authorities can more efficiently and accurately identify problems, and researchers can design experiments, the results of which will be more adequate and practically applicable.

\section{References}

[1]. Allingham, M. G., \& Sandmo, A. (1972). Income tax evasion: A theoretical analysis. Journal of public economics, 1(3-4), 323-338.

https://doi.org/10.1016/0047-2727(72)90010-2

[2]. Alm, J. (1991). A perspective on the experimental analysis of taxpayer reporting. The Accounting Review, 66(3), 577-593.

[3]. Alm, J., Jackson, B. R., \& McKee, M. (1993). Fiscal exchange, collective decision institutions, and tax compliance. Journal of Economic Behavior \& Organization, 22(3), 285-303.

https://doi.org/10.1016/0167-2681(93)90003-8

[4]. Alm, J., Kirchler, E., Muehlbacher, S., Gangl, K., Hofmann, E., Kogler, C., \& Pollai, M. (2012). Rethinking the research paradigms for analysing tax compliance behaviour. In CESifo forum (Vol. 13, No. 2, pp. 33-40). München: ifo Institut-Leibniz-Institut für Wirtschaftsforschung an der Universität München.

[5]. Alm, J., \& Melnik, M. I. (2010). Do eBay sellers comply with state sales taxes?. National Tax Journal, 63(2), 215-236.

[6]. Angrist, J. D., \& Pischke, J. S. (2010). The credibility revolution in empirical economics: How better research design is taking the con out of econometrics. Journal of economic perspectives, 24(2), 3-30. https://doi.org/10.3386/w15794

[7]. Bazart, C., \& Pickhardt, M. (2011). Fighting income tax evasion with positive rewards. Public Finance Review, 39(1), 124-149. https://doi.org/10.1177/1091142110381639 
[8]. Becker, G. S. (1968). Crime and Punishment: An Economic Approach. The Journal of Political Economy, 76(2), 169-217.

https://doi.org/10.1086/259394

[9]. Chernick, H., \& Merriman, D. (2013). Using Littered Pack Data to Estimate Cigarette Tax Avoidance in Nyc. National Tax Journal,66(3), 635-668. https://doi.org/10.2139/ssrn.2192169

[10]. Coricelli, G., Joffily, M., Montmarquette, C., \& Villeval, M. C. (2010). Cheating, emotions, and rationality: an experiment on tax evasion. Experimental Economics, 13(2), 226-247. https://doi.org/10.1007/s10683-010-9237-5

[11]. Holtermann, J. V. H. (2016). Getting Real or Staying Positive: L egal R ealism (s), L egal P ositivism and the Prospects of Naturalism in Jurisprudence. Ratio Juris, 29(4), 535-555. https://doi.org/10.1111/raju.12071

[12]. De Juan, A., Lasheras, M. A., \& Mayo, R. (1994). Voluntary tax compliant behavior of Spanish income tax payers. Public Finance $=$ Finances publiques, 49(Supplement), 90-105.

[13]. Hofmann, E., Gangl, K., Kirchler, E., \& Stark, J. (2014). Enhancing T ax Compliance through Coercive and Legitimate Power of $\mathrm{T}$ ax Authorities by Concurrently Diminishing or Facilitating Trust in $\mathrm{T}$ ax Authorities. Law \& policy, 36(3), 290-313. https://doi.org/10.1080/01442872.2019.1577375

[14]. Holtermann, J. V. H. (2019). Philosophical questions at the empirical turn. European Journal of Legal Studies, Network of Legal Empirical Scholars (NoLesLaw) Special Issue. https://doi.org/10.2139/ssrn.3324954

[15]. Kirchler, E., Hoelzl, E., \& Wahl, I. (2008). Enforced versus voluntary tax compliance: The "slippery slope" framework. Journal of Economic psychology, 29(2), 210-225. https://doi.org/10.1016/j.joep.2007.05.004

[16]. Kirchler, E. (2007). The Economic Psychology of Tax Behaviour. Cambridge University Press. https://doi.org/10.1017/CBO9780511628238

[17]. Kleven, H. J., Knudsen, M. B., Kreiner, C. T., Pedersen, S., \& Saez, E. (2011). Unwilling or unable to cheat? Evidence from a tax audit experiment in Denmark. Econometrica, 79(3), 651-692. https://doi.org/10.3982/ECTA9113

[18]. Kogler, C., Muehlbacher, S., \& Kirchler, E. (2015). Testing the "slippery slope framework" among selfemployed taxpayers. Economics Governance, 16(2), 125-142. 10.1007/s10101-015-0158-9

[19]. Muehlbacher, S., Kirchler, E., \& Schwarzenberger, H. (2011). Voluntary versus enforced tax compliance: Empirical evidence for the "slippery slope" framework. European Journal of Law and Economics, 32(1), 89-97. https://doi.org/10.1007/s10657-011-9236-9

[20]. Nordhaus, W., \& Chen, X. (2015). A sharper image? Estimates of the precision of nighttime lights as a proxy for economic statistics. Journal of Economic Geography, 15(1), 217-246. https://doi.org/10.1093/jeg/lbu010
[21]. Prinz, A., Muehlbacher, S., \& Kirchler, E. (2014). The slippery slope framework on tax compliance: An attempt to formalization. Journal of Economic Psychology, 40, 20-34. https://doi.org/10.1016/j.joep.2013.04.004

[22]. Pickhardt, M., \& Sarda, J. (2011). The size of the underground economy in Germany: a correction of the record and new evidence from the modified-cashdeposit-ratio approach. European Journal of Law and Economics, 32(1), 143-163. https://doi.org/10.1007/s10657-010-9186-7

[23]. Schneider, F. (2014). The shadow economy and shadow labor force: a survey of recent developments. IZA Discussion Paper, 82, 78-92.

[24]. Slemrod, J. \&Gillitzer C. (2014). Tax Systems. Cambridge, MA: The MIT Press.

[25]. Slemrod, J., \& Weber, C. (2012). Evidence of the invisible: toward a credibility revolution in the empirical analysis of tax evasion and the informal economy. International Tax and Public Finance, 19(1), 25-53. https://doi.org/10.1007/s10797-011-9181-0

[26]. Schmolders, G. (1959). Fiscal Psychology: A New Branch of Public Finance. National Tax Journal, 12(4), 340.

[27]. Tax Administration (2015): Comparative Information on OECD and Other Advanced and Emerging Economies. Paris: OECD Publishing, 2015.

[28]. Thaler, R. H., \& Sunstein, C. R. (2008). Nudge: Improving decisions about health, wealth, and happiness. https://doi.org/10.1007/s10602-008-9056-2

[29]. Tyler, T. R. (1990). Why people obey the law: Procedural justice. Legitimacy, and Compliance.

[30]. Tyler, T. R., \& Lind, E. A. (1992). A relational model of authority in groups. Advances in experimental social psychology, 25, 115-191. https://doi.org/10.1016/S0065-2601(08)60283-X

[31]. Torgler, B. (2016). Tax compliance and data: What is available and what is needed. Australian Economic Review, 49(3), 352-364. https://doi.org/10.1111/1467-8462.12158

[32]. Mulder, L. B., Verboon, P., \& De Cremer, D. (2009). Sanctions and moral judgments: The moderating effect of sanction severity and trust in authorities. European Journal of Social Psychology, 39(2), 255-269. https://doi.org/10.1002/ejsp.506

[33]. Wahl, I., Kastlunger, B., \& Kirchler, E. (2010). Trust in authorities and power to enforce tax compliance: An empirical analysis of the "Slippery Slope Framework". Law \& Policy, 32(4), 383-406. https://doi.org/10.1111/j.1467-9930.2010.00327.x

[34]. Wenzel, M., \& Thielmann, I. (2006). Why we punish in the name of justice: Just desert versus value restoration and the role of social identity. Social justice research, 19(4), 450-470. https://doi.org/10.1007/s11211-006-0028-2 